\title{
N uevas armas inmunológicas para la medicina del siglo XXI: Terapia biológica basada en el uso de anticuerpos monoclonales de última generación
}

\author{
Juan C Aguillón G ${ }^{1,4}$, Juan Contreras $L^{1,5}$, Andrés D otte G ${ }^{1,5}$, \\ Andrea Cruzat $C^{1,5}$, Diego Catalán $M^{1,5}$, Lorena Salazar $A^{1,6}$, \\ María Carmen Molina $S^{1,4}$, Julia G uerrero $\mathbf{P}^{1,3}$, Mercedes López $\mathbf{N}^{1}$, \\ Lilian Soto $\mathrm{S}^{2}$, Flavio Salazar-0 nfray ${ }^{1,4}$, Miguel Cuchacovich $\mathrm{T}^{2}$. \\ Biological therapy based on the use of last \\ generation monoclonal antibodies
}

The fusion of a murine B cell and a myeloma cell generates a hybridoma that produces monoclonal antibody (mAb). These murine mAb induce the HAMA (human anti-mouse antibodies) response. Murine $\mathrm{mAb}$ have been modified by genetic engineering, producing molecules with a higher proportion of human protein. At present, chimeric, humanized and fully human mAb are available. $\mathrm{mAb}$ block interactions between target molecules and their ligands or trigger the lyses of mAb-coated tumor cells. Numerous mAb have been developed using the recombinant DNA technology and several are available in the market. Trastuzumab, against HER2/neu, is useful in breast cancer; rituximab, against CD20 in B lymphocytes is useful in lymphoma; alemtuzumab, against CD52 is used in lymphoma and leukemia; daclizumab and basiliximab block the IL-2 receptor interaction and reduce acute rejection in kidney transplantion; abciximab, an antagonist of GPIIb/ IIIa platelet receptor, is used in patients undergoing acute coronary syndromes. In autoimmunity diseases, blocking tumor necrosis factor by infliximab and adalimumab has demonstrated excellent results. Thus, infliximab is useful in the treatment of rheumatoid arthritis (RA), Crohn's disease and ulcerative colitis while adalimumab is the first fully human $\mathrm{mAb}$ available for RA. Infliximab and adalimumab reduce signs and symptoms in RA and they also interfere with progression of joint damage. Finally, the direct benefits of antagonist treatment can occur at the expense of a major adverse effect in some other biological function (Rev Méd Chile 2003; 131: 1445-53).

(Key Words: Antibodies, monoclonal; Tumor necrosis factor)

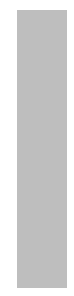

\begin{abstract}
Recibido el 11 de julio, 2003. Aceptado en versión corregida el 14 de octubre, 2003.
Financiamiento: Proyectos FONDEF D02I1088 y DID-ENL-02/13.

${ }^{1}$ Programa Disciplinario de Inmunología, Instituto de Ciencias Biomédicas (ICBM), Facultad de Medicina, Universidad de Chile, Santiago, Chile. ${ }^{2}$ Sección de Reumatología, Departamento de Medicina, Hospital Clínico Universidad de Chile, Santiago, Chile. ${ }^{3}$ Unidad de Paciente Crítico, Departamento de Medicina, Hospital Clínico Universidad de Chile, Santiago, Chile. ${ }^{4} \mathrm{PhD} .{ }^{5} \mathrm{Es}-$ tudiante de VI año de Medicina, Universidad de Chile. ${ }^{6}$ Bioquímico, estudiante de Doctorado en Ciencias Biomédicas.
\end{abstract}

Correspondencia a: Juan C Aguillón, PhD, Programa Disciplinario de Inmunología, Instituto de Ciencias Biomédicas (ICBM), Facultad de Medicina, Universidad de Chile. Independencia 1027, Santiago, Chile. Tel: 562 678.6724. Fax: 562 735.3346. E mail: jaguillo@machi.med.uchile.cl 
$\mathrm{D}$ esde comienzos del siglo pasado, con los trabajos de Emil von Behring, la inmunología ha intentado contribuir a controlar procesos agudos derivados de infecciones bacterianas, como fue el caso de sueros inmunes conteniendo anticuerpos policlonales contra la toxina tetánica y diftérica. Posteriormente, y hasta nuestros días, la utilización de sueros hiperinmunes humanos ha demostrado contribuir a prevenir o disminuir la sintomatología de infecciones virales variadas.

Durante la década 1980-89 los anticuerpos monoclonales (mAb) murinos crearon la expectativa de revolucionar el tratamiento de muchas enfermedades, debido a su gran especificidad y homogeneidad. Sin embargo, las primeras aplicaciones terapéuticas mostraron como limitación el desarrollo de respuesta inmune contra secuencias de las regiones constantes de los mAb murinos por los pacientes tratados. Esta respuesta, conocida como HAMA (human anti-mouse antibodies) tiene efectos patogénicos expresados en inflamación articular, eritema cutáneo y falla renal, entre otros. Se caracteriza además, por aumentar con la administración de dosis repetidas, trayendo como consecuencia una reducción de la actividad benéfica del mAb, probablemente derivada de la disminución de su vida media. Así, los mAb murinos sólo hallaron aplicación en los campos del diagnóstico clínico, análisis biológico en actividades productivas e investigación.

\section{LOS ANTICUERPOS MONOCLONALES MURINOS Y LOS DE ÚLTIMA GENERACIÓN}

Un mAb, por definición, corresponde al producto de un clon de linfocito $B$ con una especificidad definida y también única. A César Milstein y George Köhler, galardonados con el Premio Nobel de Medicina y Fisiología en 1984, se les atribuye el mérito de haber desarrollado la tecnología de fusionar un linfocito B con una célula de mieloma, generando un hibridoma, el que conserva tanto la propiedad del linfocito B de producir mAb como la capacidad de la célula de mieloma de replicarse en cultivo, pudiendo mantenerse en forma indefinida ${ }^{1}$.

Con el fin de superar la limitación de la respuesta HAMA de los mAb murinos, mediante la tecnología de $\mathrm{ADN}$ recombinante se modeló $\mathrm{mAb}$ que tuvieran mayor proporción de proteína humana en su estructura. Esto ha permitido el desarrollo de anticuerpos quiméricos (chAb), anticuerpos humanizados (hzAb), y más recientemente, anticuerpos monoclonales completamente humanos 0 fully human (fhAb). En los chAb, los dominios variables antígeno-específico, tanto de las cadenas livianas como de las cadenas pesadas de la molécula de inmunoglobulina, son de origen murino, mientras los dominios constantes son de origen humano. Los hzAb sólo poseen las regiones CDR (complementarity determining region) de origen murino, conservando el resto de la molécula las secuencias humanas. Los fhAb son el resultado de la expresión de genes representativos del repertorio de anticuerpos humanos, en fagos filamentosos, los cuales son seleccionados mediante la combinación in vitro con la molécula antigénica blanco.

\section{MECANISMOS DE ACCIÓN DE LOS ANTICUERPOS MONOCLONALES}

- Bloqueo de una respuesta, previniendo el acceso de mediadores solubles (citoquinas), por unión al mediador o a su receptor.

- Marcación de células tumorales por unión a antígenos específicos, permitiendo la opsonización y posterior destrucción de la célula, por lisis mediada por el mAb y dependiente del sistema del complemento.

- Desencadenamiento de señales intracelulares, inductoras de apoptosis a través de anticuerpos antiidiotipo.

- Transporte de sustancias radiactivas o citostáticas.

- Potenciación de la respuesta inmune de células $\mathrm{T}$, dirigida contra antígenos tumorales desconocidos. Entre estos se encuentran los anti-CD40, anti-CD137, anti-CTLA-4, anti-BAT2.

\section{USOS CLÍNICOS DE LOS ANTICUERPOS MONOCLONALES DE ÚLTIMA GENERACIÓN}

Dado que los nuevos mAb prácticamente no poseen las limitaciones de los mAb murinos, durante los últimos años, grupos de investigación y empresas biotecnológicas los están desarrollando. Diversos estudios han hallado usos clínicos precisos y efectivos en una variedad de disciplinas de la medicina, mientras otros tantos avanzan en su etapa de investigación (Tabla 1). 
Tabla 1. Anticuerpos monoclonales de última generación comercialmente disponibles

\begin{tabular}{|c|c|c|c|c|c|}
\hline Producto & Tipo & Blanco & Indicación & Efectos adversos & Aprobación* \\
\hline $\begin{array}{l}\text { Abciximab } \\
\left(\operatorname{ReoPro}^{\circledR}\right)\end{array}$ & Quimérico & $\begin{array}{l}\text { Receptor } \\
\text { plaquetario } \\
\text { GP IIb/IIIa }\end{array}$ & $\begin{array}{l}\text { Antitrombótico en } \\
\text { pacientes sometidos a } \\
\text { reperfusión coronaria }\end{array}$ & $\begin{array}{l}\text { Hemorragias, visión } \\
\text { borrosa, confusión, } \\
\text { lipotimia, fatiga, debilidad }\end{array}$ & 1994 \\
\hline $\begin{array}{l}\text { Rituximab } \\
\text { (Rituxan }{ }^{\circledR} \text { ) }\end{array}$ & Quimérico & $\begin{array}{l}\text { Molécula CD20 en } \\
\text { linfocitos B }\end{array}$ & $\begin{array}{l}\text { Linfoma de linfocitos B } \\
\text { y no Hodgkin }\end{array}$ & $\begin{array}{l}\text { Vértigo, calofrío, cefalea, } \\
\text { prurito, náuseas, eritema } \\
\text { cutáneo, fatiga, vómitos }\end{array}$ & 1997 \\
\hline $\begin{array}{l}\text { Daclizumab } \\
\left(\text { Zenapax }^{\circledR}\right)\end{array}$ & Humanizado & $\begin{array}{l}\text { Cadena } \alpha \text { del } \\
\text { receptor de IL-2 en } \\
\text { linfocitos T } \\
\text { activados }\end{array}$ & $\begin{array}{l}\text { Rechazo agudo de } \\
\text { trasplante renal. } \\
\text { Beneficios en } \\
\text { trasplante cardíaco }\end{array}$ & $\begin{array}{l}\text { Dolor precordial y dorsal, } \\
\text { tos, vértigo, fiebre, } \\
\text { náuseas, sudoración, } \\
\text { debilidad, vómitos }\end{array}$ & 1997 \\
\hline $\begin{array}{l}\text { Basiliximab } \\
\left.\text { (Simulect }^{\circledR}\right)\end{array}$ & Quimérico & $\begin{array}{l}\text { Cadena } \alpha \text { del } \\
\text { receptor de IL-2 en } \\
\text { linfocitos T } \\
\text { activados }\end{array}$ & $\begin{array}{l}\text { Rechazo agudo de } \\
\text { trasplante renal. } \\
\text { Beneficios en } \\
\text { trasplante cardíaco }\end{array}$ & $\begin{array}{l}\text { Dolor abdominal, tos, } \\
\text { vértigo, fiebre, debilidad, } \\
\text { agitación, temblor de } \\
\text { manos y pies }\end{array}$ & 1998 \\
\hline $\begin{array}{l}\text { Palivizumab } \\
\text { (Synagis }^{\circledR} \text { ) }\end{array}$ & Humanizado & $\begin{array}{l}\text { Proteína F del virus } \\
\text { respiratorio sincicial } \\
\text { (RSV) }\end{array}$ & $\begin{array}{l}\text { Infección por RSV en } \\
\text { niños }\end{array}$ & $\begin{array}{l}\text { Disnea, tinnitus, eritema } \\
\text { cutáneo }\end{array}$ & 1998 \\
\hline $\begin{array}{l}\text { Trastuzumab } \\
\text { (Herceptin }{ }^{\circledR} \text { ) }\end{array}$ & Humanizado & $\begin{array}{l}\text { Receptor del factor } \\
\text { crecimiento } \\
\text { HER2/neu }\end{array}$ & $\begin{array}{l}\text { Cáncer de mama } \\
\text { avanzado }\end{array}$ & $\begin{array}{l}\text { Vértigo, fiebre, calofrío, } \\
\text { cefalea, náuseas, } \\
\text { vómitos, debilidad }\end{array}$ & 1998 \\
\hline $\begin{array}{l}\text { Infliximab } \\
\text { (Remicade }^{\circledR} \text { ) }\end{array}$ & Quimérico & $\begin{array}{l}\text { Factor de necrosis } \\
\text { tumoral }\end{array}$ & $\begin{array}{l}\text { Artritis reumatoide, } \\
\text { enfermedad de Crohn, } \\
\text { colitis ulcerosa }\end{array}$ & $\begin{array}{l}\text { Infecciones virales, } \\
\text { anemia, leucopenia, } \\
\text { agitación, cefalea, } \\
\text { náuseas, diarrea }\end{array}$ & 1998 \\
\hline $\begin{array}{l}\text { Gentuzumab } \\
\left(\text { Mylotarg }^{\circledR}\right)\end{array}$ & Humanizado & $\begin{array}{l}\text { Molécula CD33 en } \\
\text { progenitores } \\
\text { mieloides }\end{array}$ & $\begin{array}{l}\text { Leucemia mieloide } \\
\text { aguda refractaria y } \\
\text { recidivante }\end{array}$ & $\begin{array}{l}\text { Trombocitopenia, fiebre, } \\
\text { calofrío, taquicardia, } \\
\text { náuseas, vómitos }\end{array}$ & 2000 \\
\hline $\begin{array}{l}\text { Alemtuzumab } \\
\text { (Campath-1 } \mathrm{H}^{\circledR}\end{array}$ & Humanizado & $\begin{array}{l}\text { Molécula CD52 en } \\
\text { linfocitos y } \\
\text { monocitos }\end{array}$ & $\begin{array}{l}\text { Linfoma y leucemia } \\
\text { crónica de células B }\end{array}$ & $\begin{array}{l}\text { Calofrío, diarrea, tos, } \\
\text { vértigo, fiebre, cefalea, } \\
\text { prurito, náuseas, vómitos }\end{array}$ & 2001 \\
\hline $\begin{array}{l}\text { Adalimumab } \\
\left.\text { (Humira }{ }^{\circledR}\right)\end{array}$ & $\begin{array}{l}\text { Completamente } \\
\text { humano }\end{array}$ & $\begin{array}{l}\text { Factor de necrosis } \\
\text { tumoral }\end{array}$ & Artritis reumatoide & $\begin{array}{l}\text { Reacción sitio de } \\
\text { inoculación, infecciones } \\
\text { respiratorias, cefalea, } \\
\text { anemia, alteraciones } \\
\text { pruebas hepáticas }\end{array}$ & 2002 \\
\hline $\begin{array}{l}\text { Omalizumab } \\
\left.\text { (Xolair }{ }^{\circledR}\right)\end{array}$ & Humanizado & $\operatorname{IgE}$ & $\begin{array}{l}\text { Asma persistente } \\
\text { moderada a severa }\end{array}$ & $\begin{array}{l}\text { Reacción sitio de } \\
\text { inoculación, infecciones } \\
\text { virales, fatiga, artralgia, } \\
\text { sinusitis, cefalea, prurito }\end{array}$ & 2003 \\
\hline
\end{tabular}

*Otorgada por Food and Drug Administration USA (FDA) 
Oncología: En la terapia contra el cáncer se han encontrado varios marcadores como blancos para su tratamiento. Dentro de éstos, destacan el receptor de tirosina-quinasa tipo 1 y los receptores de factores de crecimiento, tales como HER2/neu, el cual se encuentra sobreexpresado en cáncer gástrico, ovárico y pulmonar, y en 30\% de cáncer de mama invasivo ${ }^{3}$. En 1998 fue aprobada por la FDA (Food and Drug Administration, en Estados Unidos de Norteamérica), la indicación de un hzAb dirigido contra HER2/neu, llamado trastuzumab (Herceptin ${ }^{\circledR}$ ), para el tratamiento del cáncer de mama. Sus excelentes resultados han sido incrementados cuando se le asocia a quimioterapia convencional ${ }^{4}$.

En 1997 se aprobó el uso del chAb rituximab (Rituxan ${ }^{\circledR}$ ), dirigido contra el antígeno CD20 de los linfocitos B, en linfoma. Este chAb aumenta la proporción de mejońa de pacientes con linfoma de células B y no Hodgkin. Se suman al anterior, ibritumomab y tositumomab, ambos dirigidos contra CD20 y conjugados a un radionucleido. Cuando ibritumomab se conjuga a Ytrio-90 se denomina ibritumomab-tiuxetan (Zevalin $\left.{ }^{\circledR}\right)^{5}$ mientras tositumomab unido a Iodo-31 recibe el nombre de Bexxar ${ }^{\circledR 6}$.

Por otra parte, los resultados promisorios obtenidos en varios ensayos clínicos en que se usó alemtuzumab (Campath- $1 \mathrm{H}^{\circledR}$ ), un hzAb contra CD52, molécula que se expresa en linfocitos y monocitos, permitieron que en 2001 fuera aprobada su utilización en linfoma y en leucemia crónica de células $B^{7}$. El año 2000 se aprobó el uso de gemtuzumab (Mylotarg ${ }^{\circledR}$ ), un hzAb dirigido contra CD33 unido a una droga citostática, para el tratamiento de la leucemia mieloide aguda refractaria y recidivante ${ }^{8}$.

Con el fin de inhibir la angiogénesis mediada por el VEGF (vascular endothelial growth factor); se ha desarmollado un hzAb, rhuMAbVEG, que en modelos animales tiene efecto sinérgico con la quimioterapia ${ }^{9}$. Otro hzAb, llamado vitaxin y dirigido contra la integrina $\alpha \beta 3$, también ha demostrado interferir con la angiogénesis, mediante la inducción de apoptosis de células endoteliales ${ }^{10}$.

Se ha demostrado que los gangliósidos GM2, GD2 y GD3 se expresan en células tumorales de origen neuroectodérmico. Los hzAb KM8969 y chAb KM966, dirigidos contra GM2, potencian la lisis de células cancerosas pulmonares, mientras que chAb KM871, contra GD3, se une principalmente a melanoma ${ }^{11}$.
Trasplantología: En el área de los trasplantes, el bloqueo de la cadena $\alpha$ del receptor de interleuquina (IL)-2 con daclizumab (Zenapax ${ }^{\circledR}$ ), un hzAb, y basiliximab (Simulect ${ }^{\circledR}$ ), un chAb, reducen el riesgo de rechazo de trasplante renal y retardan su aparición sin aumentar el riesgo de infección o neoplasia ${ }^{12,13}$. Además, en trasplante cardíaco, daclizumab disminuye tanto la necesidad de prednisona como la formación de anticuerpos anti-HLA (human leucocyte antigen) ${ }^{14}$. En 1997 y 1998, respectivamente, fue aprobada la utilización de daclizumab y basiliximab contra el rechazo agudo de trasplante renal.

Infectología: El uso de mAb, en algunas áreas de la infectología, también ha demostrado ser eficaz. Así, en el caso del virus sincicial respiratorio (RSV), el hzAb palivizumab (Synagis ${ }^{\circledR}$ ), dirigido contra la proteína F del RSV y aprobado en 1998, ha mostrado buenos resultados en la prevención de infecciones respiratorias severas por RSV, disminuyendo las hospitalizaciones, la duración de éstas, y la necesidad de oxígeno suplementario, sin evidenciar reacciones adversas a esta terapia ${ }^{15}$.

Con el fin de disminuir la reacción al lipopolisacárido (LPS) de bacterias Gram (-), se han ensayado anticuerpos contra LPS, que al bloquear la interacción con su receptor CD14, se inhiba la liberación de citoquinas proinflamatorias. Así, el hzAb IC14, dirigido contra CD14, ha mostrado atenuar la fiebre inducida por LPS, la activación de leucocitos y la degranulación de granulocitos, propiedades que podrían tener grandes beneficios en sepsis severa ${ }^{16}$.

Alergología: IgE es un blanco fundamental para inhibir estas respuestas. Omalizumab y rhumAbE25, forman un complejo con IgE, disminuyendo la cantidad disponible para unirse con receptores Fc (FceR), de mastocitos y basófilos principalmente. En un ensayo clínico fase III omalizumab, al igual que rhumAb-E25, mostraron reducir los síntomas y las exacerbaciones, mejorando la calidad de vida de pacientes asmáticos. En rinitis alérgica omalizumab demostró disminuir los eventos postexposición al polen ${ }^{17}$. Recientemente, se ha aprobado la utilización de omalizumab (Xolair ${ }^{\circledR}$ ) para el tratamiento de episodios de asma persistente moderado a severo, constituyendo el primer hzAb para este propósito. 
Cardiología: Luego de la reperfusión, los neutrófilos activados pueden aumentar el daño al miocardio tras su migración a través del endotelio. Durante el proceso transmigratorio se produce la interacción de LFA-1 (formada por la unión no covalente de CD11a y CD18 -cadenas $\alpha$ y $\beta$ de LFA-1, respectivamente-), presente en la membrana de los neutrófilos, con las moléculas de adhesión intercelular ICAM-1 (CD54) expresadas en la superficie de las células endoteliales.

Estudios preclínicos con Hu23F2G (LeukArrest ${ }^{\circledR}$ ), un hzAb dirigido contra CD11/CD18, muestran que se puede limitar la magnitud del infarto y preservar la función ventricular, minimizando el daño por reperfusión ${ }^{18}$.

Por su parte, abciximab (ReoPro $\left.{ }^{\circledR}\right)$, un chAb antagonista del receptor plaquetario GPIIb/IIIa, aprobado en 1994, como antitrombótico, para la prevención de reestenosis en intervenciones coronarias percutáneas con stent para el tratamiento de angina inestable, disminuyendo el riesgo de muerte por infarto, comparado con el sólo uso de aspirina ${ }^{19}$.

\section{TERAPIA ANTAGONISTA DEL FACTOR DE NECROSIS TUMORAL (TNF) BASADA EN ANTICUERPOS MONOCLONALES DE ÚLTIMA GENERACIÓN}

El TNF es una citoquina, que además de ser central en la inmunidad innata y adquirida, participa como mediador de procesos inflamatorios y autoinmunes. Un número importante de estudios han demostrado que la administración de anticuerpos anti-TNF pueden inducir una mejoría significativa en pacientes con enfermedades mediadas inmunológicamente. En 1998 se aprobó el uso de infliximab (Remicade ${ }^{\circledR}$ ), un chAb dirigido contra TNF, en el tratamiento de la artritis reumatoide (AR) y enfermedad de Crohn, mostrando eficacia también en otras afecciones.

Enfermedad inflamatoria intestinal: El tratamiento de los pacientes que presentan enfermedad de Crohn y colitis ulcerosa intenta controlar el proceso inflamatono mediante el uso de terapias inmunomoduladoras con 5-ASA, corticoides, azatioprina, metotrexato y 6mercaptopurina. Frecuentemente los pacientes se hacen refractarios a estos tratamientos, llegando a ser un gran desafío para el manejo clínico, dado que la cirugía se reserva para los casos en que existen complicaciones. Los mecanismos patológicos que llevan a la destrucción del epitelio del tubo digestivo, apuntan a la participación de una respuesta Th1 (T helper-1) en la enfermedad de Crohn y una Th2 en la colitis ulcerosa. A través de diversos estudios, infliximab ha demostrado ser efectivo en el tratamiento de ambas enfermedades ${ }^{20}$. En la enfermedad de Crohn es capaz de mantener la remisión de los síntomas, además de disminuir la incidencia de fístulas. En tanto que, en colitis ulcerosa, induce la remisión del proceso inflamatorio ${ }^{21}$.

Enfermedades reumatológicas: El rol patológico del TNF, así como la presencia de elevados niveles en el suero ha sido establecido en pacientes con sacroileítis, AR, artritis psoriática y espondilitis anquilosante, entre otras. Infliximab, ha conseguido la remisión de los síntomas clínicos en casos que han sido refractanios a los tratamientos habituales. El mayor uso en este campo, se le ha dado en el tratamiento de la AR, donde ha demostrado gran eficacia con un bajo perfil inmunogénico. Éste ha logrado la remisión de los síntomas en prácticamente todos los pacientes que han recibido tratamiento, además de retardar la progresión del daño articular22,23. Nuestra experiencia, a través de un estudio en 20 pacientes con 4 dosis y seguidos por 22 semanas, indicó que el tratamiento con infliximab induce una mejoría clínica significativa, más de 70\% de los pacientes alcanzó ACR50 (Criterio de mejoría de 50\% del American College of Rheumatology) (sometida a publicación).

Para el tratamiento de AR, se ha aprobado la utilización de adalimumab (Humira ${ }^{\circledR}$ ), un fhAb dirigido contra TNF. Los ensayos clínicos en que adalimumab ha sido empleado, demuestran una clara disminución de signos y síntomas en la mayoría de los pacientes con AR activa, además de detener la progresión del daño articular ${ }^{24}$. Nuestros laboratorios, actualmente conducen un ensayo clínico que incluye por lo menos 100 pacientes con AR activa, tratados con adalimumab por un período de 8 meses.

Recientemente, rituximab está siendo utilizado en el tratamiento de pacientes con AR no respondedores a terapia convencional. Edwards y Cambridge publicaron el primer informe sobre la utilidad de la depleción de células B en pacientes con AR refractaria, en un estudio de 5 pacientes, todos los cuales alcanzaron ACR7025. Posteriormente, Leandro et al, demostraron que el uso de 
dosis mayores de $600 \mathrm{mg} / \mathrm{m}^{2}$ de rituximab, asociado a ciclofosfamida induce una respuesta significativa en los pacientes $\mathrm{AR}^{26}$. Simultáneamente, Edwards et al, informaron que 32\% de 122 pacientes tratados con rituximab, alcanzaron ACR50 comparado con $10 \%$ en el grupo control ${ }^{27}$.

Otro fármaco, que no siendo mAb, ha demostrado eficacia en pacientes con AR es etanercept, una proteína de fusión de tipo recombinante del receptor soluble p75 de TNF humano, que se une e inactiva al TNF. Etanercept es eficaz y capaz de inducir una remisión clínica y detener la progresión del daño radiológico en pacientes con $\mathrm{AR}^{28}$.

Infliximab ha sido utilizado en otras patologías, como la sarcoidosis sistémica complicada, lográndose la remisión de síntomas pulmonares y miopatía proximal ${ }^{29}$. En enfermedad de Still, enfermedad inflamatoria caracterizada por fiebre héctica, poliartritis, eritema cutáneo, odinofagia y adenopatías multiples, ha mostrado ser eficaz al remitir el proceso ${ }^{30}$.

En el síndrome de Behçet, en el cual existe una producción exagerada de TNF y en cuyo tratamiento los enfoques farmacológicos convencionales han mostrado no ser exitosos, la administración de infliximab, ha logrado la remisión de la enfermedad con buenos resultados, en períodos que fluctúan entre 10 semanas y 6 meses $^{31}$.

En lupus eritematoso sistémico (LES) experimental, inducido por mAb dirigidos contra ADN humano en ratones C3H.SW, el tratamiento con infliximab y Pentoxifilina, logró reestablecer los niveles de IL-1 y de TNF a aquellos obtenidos antes de la inducción del $\mathrm{LES}^{32}$.

Enfermedades dermatológicas: En muchos casos, los tratamientos actuales para el manejo de la psoriasis están asociados a efectos adversos y tóxicos. Estudios preliminares con infliximab, han mostrado efectividad del tratamiento a la cuarta semana del inicio, lográndose $91 \%$ de respuesta comparado contra placebo ${ }^{33}$.

Otros estudios muestran que infliximab media la remisión de pioderma gangrenoso y psoriasis, en pacientes con enfermedad de Crohn, detectándose el cierre de fístulas intestinales y la desaparición de placas ${ }^{34}$.

Enfermedades infecciosas: El TNF es considerado el mediador clave en el síndrome de respuesta inflamatoria sistémica y falla orgánica múltiple.
Los escasos ensayos clínicos en pacientes con sepsis, han mostrado que los beneficios de la terapia anti-TNF son leves y poco significativos en cuanto a reducir la mortalidad. Sin embargo, el uso de mAb, combinado con tratamientos de soporte, ha demostrado mayor eficacia que el de receptores solubles de TNF. Sólo un estudio, en 2.634 pacientes, ha demostrado una disminución significativa de la mortalidad ${ }^{35}$.

Las enfermedades virales, como influenza y RSV, estimulan la sobreproducción de TNF. En modelos experimentales, de animales infectados con estos agentes, se ha establecido que la inhibición de TNF disminuye la severidad, mediante reducción del reclutamiento de células proinflamatorias y citoquinas ${ }^{36}$.

Enfermedades neurológicas: Los avances dirigidos a intervenir la progresión de lumbociática, sugieren que el TNF juega un papel clave en el desarrollo de trombosis dentro del núcleo pulposo, con presencia de edema intraneural y reducción de la velocidad de conducción nerviosa. Estudios en cerdos, en que se introdujo un trozo autólogo de núcleo pulposo en la cauda equina sacrococcígea, en presencia de aplicaciones de infliximab, previno la reducción de la velocidad de conducción, el edema intraneural y episodios de trombosis. Esto constituye una aplicación inicial de la terapia anti-TNF en este tipo de patología 37 .

\section{CONSIDERACIONES FinALES}

La utilización de los $\mathrm{mAb}$ en $\mathrm{AR}$, enfermedad inflamatoria intestinal, síndrome coronario agudo e infección por RSV constituyen terapias de primera línea. En oncología, rituximab es tratamiento de elección del linfoma no Hodgkin de bajo grado/ folicular, tanto en monoterapia como en combinación con quimioterapia. En cambio trastuzumab, gentuzumab y alemtuzumab, poseen indicaciones precisas, no constituyendo el tratamiento de primera línea. Una situación equivalente ocurre con los restantes $\mathrm{mAb}$ descritos y usados para otras patologías.

El tratamiento antagonista de cualquiera de las moléculas que forman parte de la biología normal del organismo, se acompañará probablemente de exacerbación de efectos fisiológicos, que habitualmente son regulados por dicha molécula. Un 
ejemplo ilustrativo son las citoquinas, especialmente las que poseen efectos pleiotrópicos, en que la inhibición de una actividad definida, muy probablemente bloqueará otra acción, que deseamos permanezca inalterada. La Tabla 1 muestra los principales efectos adversos luego del tratamiento con $\mathrm{mAb}$ disponibles.

A pesar del éxito de la terapia anti-TNF en varias de las enfermedades abordadas, ésta se encuentra en proceso de revisión, dado que se le atribuiría una participación como factor de riesgo en el desarrollo de neoplasias linfoides, especialmente en aquellos ensayos clínicos en que la terapia se ha orientado a controlar enfermedad inflamatoria intestinal. Sin embargo, los datos preclínicos observados con el uso de infliximab, no proporcionan evidencia suficiente para definir una relación causa-efecto entre la terapia antagonista de TNF y el desarrollo de cáncer linfoide y no-linfoide ${ }^{38}$.

No se puede desconocer el papel que juega el TNF en la inmunidad contra organismos intracelulares. En los ensayos clínicos con terapia anti-TNF, aunque no propio, un porcentaje de pacientes, luego de la administración de varias dosis de infliximab, desarrollan infecciones con microorga-

\section{REFERENCIAS}

1. Kohier G, MiLSTein C. Continuous cultures of fused cells secreting antibody of predefined specificity. Nature 1975; 256: 495-7.

2. Giennie MJ, Johnson PW. Clinical trials of antibody therapy. Immunol Today 2000; 21: 403-10.

3. Baselga J, Mendelsohn J. Type I receptor tyrosine kinases as targets for therapy in breast cancer. J Mammary Gland Biol Neoplasia 1997; 2: 165-74.

4. Siamon DJ, Leyland-Jones B, Shak S, Fuchs H, Paton V, BAJAMONDE A ET AL. Use of chemotherapy plus a monoclonal antibody against HER2 for metastatic breast cancer that overexpresses HER2. N Engl J Med 2001; 344: 783-92.

5. CHESON BD. Radioimmunotherapy of nonHodgkin lymphomas. Blood 2003; 101: 391-8.

6. Cheson B. Bexxar (Corixa/GlaxoSmithKline). Curr Opin Investig Drugs 2002; 3: 165-70.

7. FuYNN JM, Byrd JC. Campath-1H monoclonal antibody therapy. Curr Opin Oncol 2000; 12: 574-81. nismos intracelulares. Keane et al, mediante un estudio retrospectivo en un total de 147.000 pacientes tratados con infliximab, detectaron la reactivación de tuberculosis en 70 casos $^{39}$. Lo anterior pudiera relacionarse a un desbalance en la red de citoquinas, impidiendo la participación de citoquinas vitales en el control de agresores intracelulares. Sin embargo, a diferencia de interferón $\gamma$ e IL-12, el TNF no ha probado tener un papel protector en la respuesta inmune antimicobacterio ${ }^{40}$.

Cabe destacar, que en el caso de países en vías de desarrollo, una limitante importante para el uso de estas terapias emergentes la establece lo elevado de sus costos. Se estima que un paciente con AR requiere no menos de US $\$ 10.000 /$ año para su tratamiento con infliximab o adalimumab. Esta situación no difiere significativamente para cualquiera de los otros mAb comerciales.

Finalmente, debemos mencionar que esta revisión se ha referido a los mAb que han logrado un estado de avance importante en su desarrollo y aplicación, muchos de ellos comercialmente disponibles, mientras que otros, no mencionados, ofrecen un futuro promisorio, con aplicaciones en áreas de la medicina aún no sospechadas.

8. Stanisic S, Kalaycio M. Treatment of refractory and relapsed acute myelogenous leukemia. Expert Rev Anticancer Ther 2002; 2: 287-95.

9. Margolin K, Gordon MS, Holmgren E, Gaudreault J, Novotny W, Fyfe G et aL. Phase Ib trial of intravenous recombinant humanized monoclonal antibody to vascular endothelial growth factor in combination with chemotherapy in patients with advanced cancer: pharmacological and long-term safety data. J Clin Oncol 2001; 19: 851-6.

10. Gutheil JC, Campbeil TN, Pierce PR, Watkins JD, Huse WD, BodKIN DJ ET AL. Targeted antiangiogenic therapy for cancer using Vitaxin: a humanized monoclonal antibody to the integrin alpha-beta3. Clin Cancer Res 2000; 6: 3056-61.

11. Hanai N, Nakamura K, Shitara K. Recombinant antibodies against ganglioside expressed on tumor cells. Cancer Chemother Pharmacol 2000; 46 Suppl: S13-17.

12. Bumgardner GL, HaRdie I, Johnson RW, Lin A, Nashan B, Pescovitz MD et al. Phase III Daclizum- 
ab Study Group. Results of 3 years phase III clinical trials with daclizumab prophylaxis for prevention of acute rejection after renal transplantation. Transplantation 2001; 72: 839-45.

13. Folkmane I, Bicans J, Amerika D, Chapenko S, Murovska M, Rosentals R. Low Rate of Acute Rejection and Cytomegalovirus Infection in Kidney Transplant Recipients With Basiliximab. Transplantation Proceedings 2001; 33: 3209-10.

14. Beniaminovitz A, Itescu S, Lietz $K$, Donovan $M$, BURKE EM, GROFF BD ET AL. prevention of rejection in cardiac transplantation by blockade of the interleukin-2 receptor with a monoclonal antibody. N Engl J Med 2000; 342: 613-9.

15. Groothuis JR, Nishida H. Prevention of respiratory syncytial virus infections in high-risk infants by monoclonal antibody (palivizumab). Pediatr Int 2002; 44: 235-41.

16. Spek CA, Verbon A, Aberson H, Pribble JP, McELGUNn CJ, TuRner T et al. Treatment with an antiCD14 monoclonal antibody delays and inhibits lipopolysaccharide-induced gene expression in humans in vivo. J Clin Immunol 2003; 23: 132-40.

17. NeLSON HS. Advances in upper airway diseases and allergen immunotherapy. J Allergy Clin Immunol 2003; 111 (3 Suppl): S793-8.

18. Rusnak JM, Kopecky SL, Clements IP, GibBons RJ, Holland AE, Peterman HS et al. An anti-CD11/ CD18 monoclonal antibody in patients with acute myocardial infarction having percutaneous transluminal coronary angioplasty (the FESTIVAL study). Am J Cardiol 2001; 88: 482-7.

19. NuRDEN P. GPIIb-IIIa inhibitors. Transfus Clin Biol 2001; 8: 114-22.

20. Blam ME, Stein RB, Lichtenstein GR. Integrating anti-tumor necrosis factor therapy in inflammatory bowel disease: current and future perspectives. Am J Gastroenterol 2001; 96: 1977-97.

21. SANDBORN WJ. Strategies targeting tumor necrosis factor in Crohn's disease. Acta Gastroenterol Belg 2001; 64: 170-2.

22. Lipsky PE, Van Der HejJe DM, St Clair EW, Furst DE, Breedveld FC, KaLden JR et al. Infliximab and methotrexate in the treatment of rheumatoid arthritis. N Engl J Med 2000; 343: 1594-602.

23. TAYLOR PC. Anti-tumor necrosis factor therapies. Curr Opin Rheumatol 2001; 13: 164-9.

24. RAU R. Adalimumab (a fully human anti-tumor necrosis factor a monoclonal antibody) in the treatment of active rheumatoid arthritis: The initial results of five trials. Ann Rheum Dis 2002; 61 (suppl II): ii70-ii73.

25. EDWARDS JC, CAMBRIDGE G. Sustained improvement in rheumatoid arthritis following a protocol designed to deplete B lymphocytes. Rheumatology 2001; 40: 205-11.

26. Leandro MJ, Edwards JCW, Cambridge G. Clinical outcome in 22 patients with rheumatoid arthritis treated with B lymphocyte depletion. Ann Rheum Dis 2002; 61: 883-8.

27. EdWARdS JCW, SZCEPANSKI L, Szechinski J. Efficacy and safety of Rituximab, a B-cell targeted chimeric monoclonal antibody: A randomized placebocontrolled trial in patients with rheumatoid arthritis (abstract). Arthritis Rheum 2002; 46: S197.

28. Genovese MC, Bathon JM, Martin RW, Fleischmann RM, TESSER JR, Schiff MH ET AL. Etanercept versus methotrexate in patients with early rheumatoid arthritis: two years radiographic and clinical outcomes. Arthritis Rheum 2002; 46: 1443-50.

29. Yee AM, Pochapin MB. Treatment of complicated sarcoidosis with infliximab anti-tumor necrosis factor-alpha therapy. Ann Intern Med 2001; 135: 27-31.

30. Cavagna L, Caporali R, Epis O, Bobbio-Paluavicini F, MoNTECUCCO C. Infliximab in the treatment of adult Still's disease refractory to conventional therapy. Clin Exp Rheumatol 2001; 19: 329-32.

31. Goossens PH, Verburg RJ, BReEdveld FC. Remission of Behçet's syndrome with tumour necrosis factor alpha blocking therapy. Ann Rheum Dis 2001; 60: 637.

32. Segal R, Dayan M, Zinger H, Mozes E. Suppression of experimental systemic lupus erythematosus (SLE) in mice via TNF inhibition by an anti-TNF alpha monoclonal antibody and by pentoxiphylline. Lupus 2001; 10: 23-31.

33. Chaudhari U, Romano P, Mulcahy LD, Dooley LT, BaKer DG, GotTlieb AB. Efficacy and safety of infliximab monotherapy for plaque-type psoriasis: a randomized trial. Lancet 2001; 357: 1842-7.

34. TAN MH, Gordon M, Lebwohl O, George J, Lebwohl MG. Improvement of pyoderma gangrenosum and psoriasis associated with Crohn disease with anti-tumor necrosis factor alpha monoclonal antibody. Arch Dermatol 2001; 137: 930-3. 
35. ReinharT K, KarzaI W. Anti-tumor necrosis factor therapy in sepsis: update on clinical trials and lessons learned. Critical Care Medicine 2001; 29 (7 Suppl): S121-5.

36. Husseld T, Pennycook A, Openshaw PJ. Inhibition of tumor necrosis factor reduces the severity of virus specific lung immunopathology. Eur J Immunol 2001; 31: 2566-73.

37. OlMARKER K, Rydevik B. Selective inhibition of tumor necrosis factor-alpha prevents nucleus pulposus induced thrombus formation, intraneural edema, and reduction of nerve conduction velocity: possible implications for future pharmacologic treatment strategies of sciatica. Spine 2001; 26: 863-9.
38. Cohen RB, Dittrich KA. Anti-TNF therapy and malignancy, a critical review. Can J Gastroenterol 2001; 15: 376-84.

39. Keane J, Gershon S, Wise RP, Mirabile-Levens E, Kasznica J, Schwieterman WD et al. Tuberculosis associated with infliximab, a tumor necrosis factor alpha-neutralizing agent. N Engl J Med 2001; 345: 1098-104.

40. De Jong R, Altare F, Haagen IA, Elferink DG, Boer T, Van Breda VRiesman PJ et al. Severe mycobacterial and Salmonella infections in interleukin-12 receptor-deficient patients. Science 1998; 280: 1435-58. 